\title{
Spatial differentiation and temporal dynamics of drained raised bogs in Western Siberia
}

\author{
Anna Sinyutkina ${ }^{1 *}$ \\ ${ }^{1}$ Siberian Federal Scientific Centre of Agro-Bio Technologies of the Russian Academy of Sciences, \\ Siberian Research Institute of Agriculture and Peat, Russia
}

\begin{abstract}
This study analysed the influence of drainage on the vegetation cover of raised bogs in the taiga zone of Western Siberia. The study was based on a temporal analysis of Landsat satellite imagery data using the normalised difference vegetation index (NDVI) for the period from 19752020. We investigated four key sites within drained raised bogs. The analysis was not carried out using absolute NDVI values; rather, the ratio of the NDVI values of drained bogs to the NDVI values of a similar pristine bog was used. Four stages of the vegetation dynamics of drained bogs were determined. In the first stage, including the period before drainage, the NDVI values were close to those of the pristine site, which confirms that there are similar conditions before drainage. The second stage, from 19892001(2002), is characterised by a decrease in NDVI values relative to the pristine bog. This was probably due to the degradation of moss vegetation, which is a sensitive indicator of a decrease in the water table level in the absence of a significant growth of the tree layer. Furthermore, since the 2000 s, there has been an increase in the NDVI values and they have stabilised at the level of a pristine bog.
\end{abstract}

\section{Introduction}

In the taiga zone of Western Siberia, the drainage of raised bogs was carried out from the 1960 s to the1980s, mainly for agricultural and forestry activities, but also for peat extraction. Drained mires occupy more than $500 \mathrm{~km}^{2}$ (less than $1 \%$ of the total wetland area), and among them, pine dwarf-shrub sphagnum raised bogs cover only $130 \mathrm{~km}^{2}$. However, despite their small area, these sites are at risk from peat fires. About $30 \%$ of their total area burned in several different years $(1998,2014,2016,2019) \quad\left[\begin{array}{ll}1, & 2 \text {, }\end{array}\right.$ https://firms2.modaps.eosdis.nasa.gov/map]. Draining did not result in increased wood biomass, mainly because of poor mineral nutrition. The effect of drainage on vegetation was limited to a change in the species composition, mainly of moss and dwarf shrub cover. Currently, the drained bogs are not used, and the ditch culvert capacity has decreased due to overgrowing. Within the drained mires of the taiga zone of Western Siberia, there are no long-term field studies to assess the impact of drainage and the further development of vegetation cover. Thus, the use of multi-time satellite images is generally accepted, and it is sometimes the only method available for the long-term monitoring of wetlands. In particular,

* Corresponding author: ankalaeva@yandex.ru 
many studies have shown that Landsat data can be used to model the characteristics of the vegetation cover of mires; this is an inexpensive and effective method for assessing carbon accumulation in mires of different biogeographic regions [3-9]. Despite its prospects and high scientific and practical significance, for the territory of the taiga zone of Western Siberia, studies on monitoring ecosystem processes using satellite data within wetlands are not numerous [10].

The aim of the study is to evaluate the transformation of vegetation cover after drainage and the intensity of the processes of the self-restoration or degradation of the drained bogs based on a temporal analysis of Landsat satellite imagery data using the normalised difference vegetation index (NDVI).

\section{Objects and methods}

\subsection{Study sites}

We investigated five key sites within drained and pristine raised bogs in the south-eastern part of Western Siberia within the Tomsk region. The sites were located within interfluve valleys and terraces in the basin of the Chaya River (Middle Ob basin) and on the left bank terrace of the Ket River (table 1). The studies were conducted within the pine dwarf-shrub Sphagnum raised bogs. The most dominant woody species is Pinus sylvestris. The tree height ranges from 0.5 to $5 \mathrm{~m}$, with a tree crown projective cover below $10 \%$. The dwarf-shrubs Ledum palustre, Chamaedaphne calyculata, Andromeda polifolia and other species are widespread, with an average cover of $70-90 \%$. In the moss layer, species of the genus Sphagnum dominate, including Sphagnum fuscum, S. magellanicum, S. balticum and $S$. angustifolium. Moss cover reaches $90-100 \%$ [11]. The peat deposit thickness ranges mainly from 1 to $4 \mathrm{~m}$, sometimes reaching $6 \mathrm{~m}$.

Table 1. Key sites characteristics.

\begin{tabular}{|c|c|c|c|c|}
\hline \multicolumn{2}{|c|}{ Key site } & Coordinates & Geographical position & Altered by human activity \\
\hline 1 & Kolpashevo & $58^{\circ} 19^{\prime} \mathrm{N}$ & Ket River terrace & Forestry drainage \\
& bog (K) & $83^{\circ} 07^{\prime} \mathrm{E}$ & & \\
\hline 2 & Ust-Bakchar & $57^{\circ} 35^{\prime} \mathrm{N}$ & Bakchar River terrace & Drainage for peat extraction \\
& bog (UB) & $82^{\circ} 16^{\prime} \mathrm{E}$ & & \\
\hline 3 & Bakchar bog & $56^{\circ} 54^{\prime} \mathrm{N}$ & North-eastern part of Great & Forestry drainage \\
& $(\mathrm{BB})$ & $82^{\circ} 41^{\prime} \mathrm{E}$ & $\begin{array}{c}\text { Vasyugan Mire, Bakchar } \\
\text { and Iksa Rivers interfluve }\end{array}$ & \\
\hline 4 & Iksa bog (IB) & $56^{\circ} 51^{\prime \prime} \mathrm{N}$ & North-eastern part of Great & Forestry drainage \\
& & $83^{\circ} 16^{\prime} \mathrm{E}$ & Vasyugan Mire, Iksa and & \\
& & & Shegarka Rivers interfluve & \\
\hline 5 & Bakchar bog & $56^{\circ} 58^{\prime} \mathrm{N}$ & North-eastern part of Great & Pristine bog \\
& (BBpristine) & $82^{\circ} 37^{\prime} \mathrm{E}$ & Vasyugan Mire, Bakchar & \\
& & & and Iksa Rivers interfluve & \\
\hline
\end{tabular}

Drained pine dwarf-shrub Sphagnum raised bogs occupy $130 \mathrm{~km}^{2}$ within the southeastern part of Western Siberia. Drainage was carried out in the 1970s and 1980s via a network of open ditches with a distance of $150-180 \mathrm{~m}$ on the drained site for forestry (the Bakchar, Iksa and Kolpashevo bogs) and 20-60 m on the drained site for peat extraction (the Ust-Bakchar bog); the planned width was 1-2 m, with a depth of up to $1 \mathrm{~m}$. Draining did not result in increased wood biomass, mainly because of poor mineral nutrition [1]. The lack of planting and repair of the drainage network has led to the development of the self-restoration processes of some drained bogs. Depending on the initial drainage rate and the current state of the drainage network, bogs are at different stages of the self-restoration or degradation of 
vegetation cover. A key site in the Klyuch River basin within the pristine part of the Bakchar bog was selected as an object of comparison.

\subsection{GIS mapping methods}

Temporal analyses of bog ecosystem dynamics were conducted for the bog contours on the basis of the vegetation maps of key sites. These maps were drawn using the classification of Landsat satellite data using the Semi-Automatic Classification Plugin (QGiS 3.8). The GIS mapping of drained bogs included the following steps: 1) Creating shapefiles, including rectangular contours that limit the territory of key sites. The contour size depended on the properties of the spatial distribution of the plant community within the bogs, the bogs' area and the area of the network of drainage ditches. The area of the Kolpashevo key site is 106 $\mathrm{km}^{2}$, the Bakchar key site is $44 \mathrm{~km}^{2}$, the Iksa key site is $25 \mathrm{~km}^{2}$ and the Ust-Bakchar key site is $4 \mathrm{~km}^{2}$. 2) The choice of satellite images covers the territory under study. We used an image with a shooting date in the middle of the vegetation period and without clouds. We chose the image from 17 July 2019 for key sites within the Bakchar and Iksa bogs and 31 July 2020 for the Kolpashevo and Ust-Bakchar key sites. 3) A signature list was created with the use of the data of a field study conducted in summer 2019. The key sites were divided into 6-8 classes - forest, field, swamp forest, lags, hummock-hollow bog and pine dwarf-shrub sphagnum drained and pristine bogs. Each of the classes included more than five ROI polygons. 4) The classification of satellite images was conducted with the use of visible and infrared bands (27 bands of the Landsat 8 OLI/TIRS) using the maximum likelihood method. The classification results were saved as shapefiles for further analyses.

For analyses of the temporal dynamics of the NDVI, we used the contours of vegetation maps corresponding to pine dwarf shrub sphagnum drained bogs. Landsat satellite data for the period from 1973-2020 were used to assess the state of bogs before the drainage, the effects of the drainage and the modern processes of the self-restoration or degradation of the bogs within key sites. The NDVI was determined using a raster calculator of the SemiAutomatic Classification Plugin. We used data from the Landsat 8 satellite for the period from May-September to identify patterns of the seasonal dynamics of the NDVI for 20192020, but to calculate the average values for the growing season by year, we limited ourselves only to summer values (June-August). Due to the high clouds characteristic of the territory under study, the number of images for the period from May-September was only 2 to 8 per year for the period 2013-2020. For an earlier period of shooting (1999-2012, Landsat 7), due to a defect in the equipment, there were even fewer suitable images (1-3 during the growing season); preference was given to images taken from July-August. It should be noted that the continuous series of Landsat 1-5 surveys for the period 1973-1999 is missing, but we managed to obtain data for the period before drainage (1973-1978) and the period in the first years after drainage (1989-1990). In total, satellite data for 77 survey dates were used for analysis, on the basis of which 456 NDVI values for field study points and 252 NDVI values for the vegetation contours of key sites were determined. In order to exclude the influence of NDVI dynamics associated with the peculiarities of the growing season and possible errors associated with the use of a time-heterogeneous data series, a retrospective analysis was carried out using not absolute NDVI values but the ratio of the NDVI values of drained bogs to the NDVI values of the pristine site on the Bakchar bog on each survey date. 


\section{Results and discussion}

\subsection{State of vegetation cover and spatial differentiation of the drained raised bogs within key sites}

Both pristine and drained pine dwarf-shrub sphagnum plant communities are characterised by limited species of vascular plants due to the oligotrophic conditions of raised bogs, even after drainage. Pinus sylvestris, Chamaedaphne calyculata, Ledum palustre and Rubus chamaemorus occurred in all investigated plots. We highlight the change of the species composition of the tree layer within the key site with the greater draining effect only (the Ust-Bakchar bog), evident in the appearance of birch in the pine dwarf-shrub Sphagnum plant community. Also, the height and closeness of the tree layer did not significantly change [1].

The analysis of the NDVI for the vegetation periods from 2019-2020 was carried out to compare the NDVI values with the characteristics of modern vegetation cover. The mean value of the NDVI was 0.70 ; it varies in the interval $0.68-0.72$. The key sites were divided into three groups based on the values of the NDVI of drained bogs relative to the pristine bog (fig. 1). We included the Ust-Bakchar bog in the first group. We explain the higher NDVI values characteristic of both points of the Ust-Bakchar bog by the presence of birch in the species composition of the tree layer and the wide development of the dwarf shrub layer, which reaches a projective coverage of up to $100 \%$. The assumption about the growth of the NDVI being due to the growth of deciduous species was confirmed by analysing the seasonal dynamics of the NDVI. The NDVI values in the Ust-Bakchar bog in May (as of 3 May 2019) are significantly lower (0.47) compared to other sites, where the NDVI varies from 0.55 in the pristine bog to $0.58-0.61$ in drained bogs. The second group contains the Kolpashevo bog as well as one part of the Iksa bog. They are characterised by average NDVI values among the key sites relative to the NDVI of a pristine bog. It should be noted that despite the similarity in the NDVI values of the pristine bog and the drained sites at the present stage of vegetation dynamics, the species composition differs between the sites. Probably, in some cases, the NDVI value is achieved due to a more developed tree layer with sparse dwarf shrub and moss cover. The NDVI values are slightly lower (0.68-0.69) in comparison with the pristine bog in the other part of the Iksa bog and the Bakchar bog, which form the third group of sites. In accordance with the results of the cluster analysis conducted on the basis of field data, it was noted that these sites are characterised by the maximum degree of self-restoration of vegetation cover [1]. Thus, an increase in NDVI values relative to a pristine bog is an indicator of the transformation of vegetation cover; with the development of self-restoration processes, the NDVI decreases slightly.

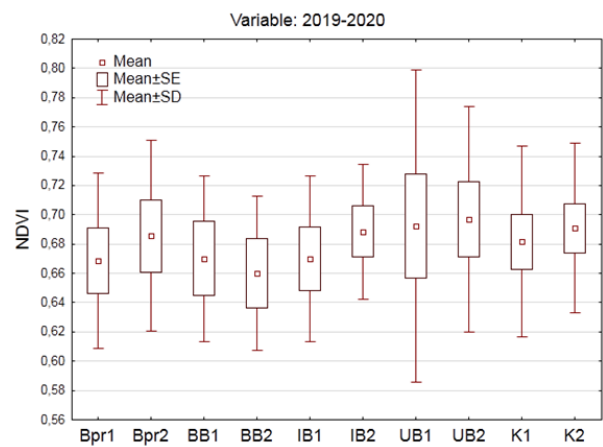

Fig. 1. Diagram with NDVI for all key sites for 2019-2020. See table 1. 


\subsection{Assessment of temporal dynamics of drained raised bogs}

Four stages of the vegetation dynamics of drained bogs were determined on the basis of temporal analyses of the NDVI. Similar patterns of NDVI dynamics are characteristic of most sites (mainly the Bakchar, Iksa and Kolpashevo bogs) (fig. 2). At the first stage, including the period before drainage, the NDVI values were close to those of the pristine site, which confirms that there were similar conditions before drainage. The second stage from 19892001(2002) is characterised by a decrease in the NDVI relative to that of the pristine bog. This was probably due to the degradation of moss vegetation, which is a sensitive indicator of a decrease in the water table level in the absence of a significant growth of the tree layer. Furthermore, since the $2000 \mathrm{~s}$, there has been an increase in NDVI values and they have stabilised at the level of a pristine bog. The Ust-Bakchar bog is characterised by a more significant decrease of the NDVI in the first years after drainage. This is probably due to a more significant degradation of the moss cover due to a larger decrease in the water table level. By 1999-2000, the NDVI had recovered to the level of a pristine bog. The earlier increase in the NDVI in comparison with the rest of the plots is probably due to the intensive growth of the dwarf shrub layer, in particular, the increase in the cover of Vaccinium uliginosum, which is an indicator of drainage. From 2002-2010, we again observed a decrease of the NDVI, which is probably due to a fire that occurred during this period. After 2010 , the NDVI values stabilise at a level above those of the pristine bog, which has already been noted above.
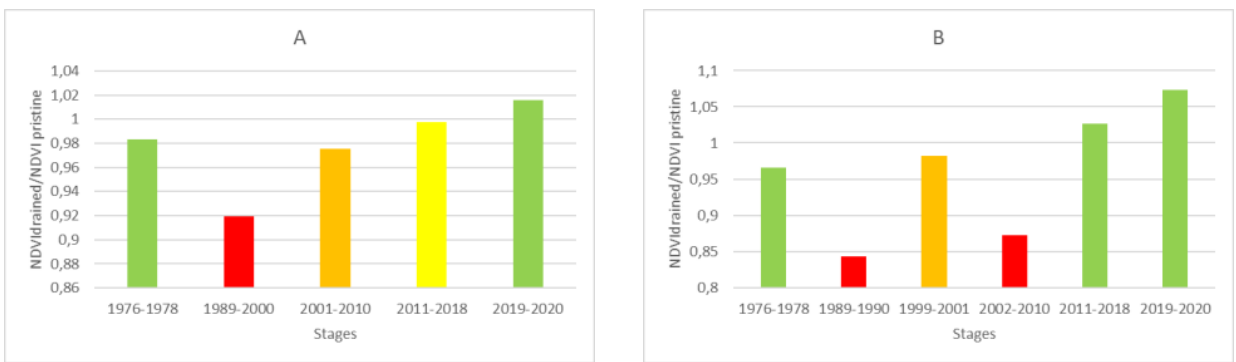

Fig. 2. Temporal dynamics of the vegetation of drained bogs. A - average for key sites (except UstBakchar bog); B - Ust-Bakchar bog.

\subsection{Application of Landsat data in wetland dynamics research}

Many studies have shown that Landsat data can be used to model the characteristics of wetland vegetation at different stages of recovery; this is an inexpensive and effective method for estimating the carbon storage in the wetlands of different biogeographic regions. At the same time, the authors emphasise the small number of complex studies on the analysis of the spectral characteristics of wetlands and the complexity of mapping wetlands in comparison with forests due to their high spatial heterogeneity, temporal dynamics and high surface humidity. Mapping wetlands requires the development of approaches for the geoinformation mapping of wetlands using satellite data $[3,6]$.

Knox et al. [12] evaluated the feasibility of using Landsat data as a simple and low-cost tool to assess the balance of recovering wetlands (California, USA). The study showed that plant indices obtained from Landsat data can be used to model photosynthesis within wetlands. Methods for the long-term monitoring of wetlands based on the analysis of multitemporal images are presented in [4-9]. The authors tested the possibility of using satellite data to assess the characteristics of wetlands' vegetation cover in different regions of the world and developed time series of biophysical characteristics for long-term trend analysis 
and seasonal dynamics, including the NDVI in their analysis. Amani et al. [3] studied wetland classes using a combination of field and satellite data (Canada). That study concluded that the near infrared and red channels are the most useful spectral ranges for the differentiation of wetlands classes, and they have a high potential for monitoring wetlands.

\section{Conclusions}

Thus, at most key sites, we did not detect the expected increase in the NDVI which must be happened due to an increase in the production of trees and dwarf shrubs in response to a water table drawdown. On the contrary, as a result of drainage, vegetation degradation has been observed, leading to a decrease in the NDVI in the first years after drainage. Since the beginning of the $2000 \mathrm{~s}$, there has been an increase in NDVI values and they have stabilised at the level of a pristine bog.

A more significant transformation of the vegetation cover is characteristic of the UstBakchar bog, which was drained for the purpose of peat extraction. In addition, successional changes of vegetation under the influence of a decrease in the water table level are influenced by fires that periodically occur in this bog as a result of a constantly low water level. For key sites drained for forestry, the effect of drainage was less significant, and currently the NDVI values are close to those of a pristine bog.

Funding: The research was carried out with financial support from the RSF in the framework of the scientific project No. 19-77-00010.

\section{References}

1. A. Sinyutkina, Catena 205 (2021). №. 105464.

2. A. A. Sinyutkina, L. P. Gashkova, N. G. Koronatova, A. A. Maloletko, N. P. Mironycheva-Tokareva, I. V. Russkikh, O. V. Serebrennikova, E. B. Strel'nikova, E. K. Vishnyakova Yu. A. Kharanzhevskaya, IOP Conf. Ser.: Earth Environ. Sci. 408, 012037 (2020)

3. M. Amani, B. Salehi, S. Mahdavi, B. Brisco, ISPRS J. Photogramm Remote Sens. 144, 119-136 (2018).

4. A. Davranche, G. Lefebvre, B. Poulin, Remote Sensing of Environment 114, 552-562 (2010)

5. S. Ghosh, D. R. Mishra, A. A. Gitelson, Remote Sensing of Environment 173, 39-58 (2016)

6. C. Ludwig, A. Walli, C. Schleicher, J. Weichselbaum, M. Riffler, Remote Sensing of Environment 224, 333-351 (2019)

7. C. Petus, M. Lewis, D. White, Ecological Indicators 34, 41-52 (2013)

8. L. M. Rebelo, C. M. Finlayson, N. Nagabhatla, J. of Environmental Management 90, 2144-2153 (2009)

9. C. Vittorio, A. Georgakakos, Remote Sensing of Environment 204, 1-17 (2018)

10. E.A. Dyukarev, M.N. Alekseeva, E.A. Golovatskaya, Exploring the Earth from space 2, 38-51 (2017)

11. E.D. Lapshina Mire vegetation of the South-East of Western Siberia. NSU, Novosibirsk (2010)

12. S. H. Knox, I. Dronova, C. Sturtevant, P. Y. Oikawa, J. H. Matthes, J. Verfaillie, D.

Baldocchi, Agricultural and Forest Meteorology 237-238, 233-245 (2017) 